\title{
Effects of pulse width and repetition rate of pulsed laser on kinetics and production of singlet oxygen luminescence
}

\author{
Defu Chen*, Ying Wang ${ }^{\dagger}$, Buhong Li ${ }^{\star}$, , Huiyun Lin ${ }^{\star}$, , \\ Xuechun Lin ${ }^{\uparrow}$ and Ying $\mathrm{Gu}^{\dagger, \|}$ \\ ${ }^{*}$ School of Information and Electronics \\ Beijing Institute of Technology, Beijing 100081, P. R. China \\ ${ }^{\dagger}$ Department of Laser Medicine \\ Chinese People's Liberation Army General Hospital \\ Beijing 100853, P. R. China \\ $\$$ Key Laboratory of OptoElectronic Science and \\ Technology for Medicine of Ministry of Education \\ Fujian Normal University, Fujian 350007, P. R. China \\ $\S_{\text {Fujian Provincial }}$ \\ Key Laboratory for Photonics Technology \\ Fujian Normal University, Fujian 350007, P. R. China \\ "Laboratory of All-Solid-State Light Sources \\ Institute of Semiconductors \\ Chinese Academy of Sciences, Beijing 100083, P. R. China \\ "guyinglaser301@163.com
}

Received 11 October 2015

Accepted 17 November 2015

Published 13 January 2016

\begin{abstract}
Pulsed and continuous-wave (CW) lasers have been widely used as the light sources for photodynamic therapy (PDT) treatment. Singlet oxygen $\left({ }^{1} \mathrm{O}_{2}\right)$ is known to be a major cytotoxic agent in type-II PDT and can be directly detected by its near-infrared luminescence at $1270 \mathrm{~nm}$. As compared to CW laser excitation, the effects of pulse width and repetition rate of pulsed laser on the kinetics and production of ${ }^{1} \mathrm{O}_{2}$ luminescence were quantitatively studied during photosensitization of Rose Bengal. Significant difference in kinetics of ${ }^{1} \mathrm{O}_{2}$ luminescence was found under the excitation with various pulse widths of nanosecond, microsecond and $\mathrm{CW}$ irradiation with power of $20 \mathrm{~mW}$. The peak intensity and duration of ${ }^{1} \mathrm{O}_{2}$ production varied with the pulse widths for pulsed laser excitation, while the ${ }^{1} \mathrm{O}_{2}$ was generated continuously and its production reached a steady state with $\mathrm{CW}$ excitation. However, no significant difference $(P>0.05)$ in integral
\end{abstract}

\|Corresponding author.

This is an Open Access article published by World Scientific Publishing Company. It is distributed under the terms of the Creative Commons Attribution 4.0 (CC-BY) License. Further distribution of this work is permitted, provided the original work is properly cited. 


\begin{abstract}
${ }^{1} \mathrm{O}_{2}$ production was observed. The results suggest that the PDT efficacy using pulsed laser may be identical to the $\mathrm{CW}$ laser with the same wavelength and the same average fluence rate below a threshold in solution.
\end{abstract}

Keywords: Photodynamic therapy; pulsed laser; continuous-wave laser; singlet oxygen luminescence.

\section{Introduction}

Photodynamic therapy (PDT) is an effective therapeutic modality that utilizes a light source to excite photosensitizer (PS) for the treatment of malignant and nonmalignant conditions, and singlet oxygen $\left({ }^{1} \mathrm{O}_{2}\right)$ is known to be the primary cytotoxic agent generated photochemically in type-II PDT. ${ }^{1,2}{ }^{1} \mathrm{O}_{2}$ can be detected directly by its nearinfrared (NIR) luminescence emission at around $1270 \mathrm{~nm},{ }^{3}$ and ${ }^{1} \mathrm{O}_{2}$ NIR luminescence was investigated as a dosimetric predictor of PDT responses both in vitro and in vivo. ${ }^{4-6}$

PDT involves three major components: light, PS and molecular oxygen. ${ }^{7}$ Continuous-wave (CW) and pulsed lasers were widely used as excitation light sources for activating PS in PDT, and the effects of PS types, ${ }^{8,9}$ oxygen concentration ${ }^{10,11}$ on ${ }^{1} \mathrm{O}_{2}$ production have been intensively evaluated, respectively. However, as one of the three essential components of PDT, the effects of laser parameters (i.e., pulse width, repetition rate) for pulsed lasers on the kinetics and production of ${ }^{1} \mathrm{O}_{2}$ luminescence have not been fully explored.

The aim of the study was to examine the effects of pulse width and repetition rate of pulsed laser on the kinetics and production of ${ }^{1} \mathrm{O}_{2}$ luminescence during photosensitization by directly detecting its NIR luminescence. Water-soluble Rose Bengal (RB) was used as model PS, and RB mediated ${ }^{1} \mathrm{O}_{2}$ luminescence under the excitation with various pulse widths and repetition rates were quantitatively studied by using a time-resolved ${ }^{1} \mathrm{O}_{2}$ luminescence detection system.

\section{Materials and Methods}

\subsection{Chemicals}

For generation of ${ }^{1} \mathrm{O}_{2}, \mathrm{RB}$ (Sigma-Aldrich, St. Louis, MO, USA) was used as a model PS in the solutionbased measurements. A $100 \mu \mathrm{M}$ RB was prepared as stock solution in initially air-statured phosphate buffered saline (PBS) at $\mathrm{pH} 7.5$, and stored at $4{ }^{\circ} \mathrm{C}$ in the dark. $1.00 \mu \mathrm{M}$ RB was freshly prepared from the stock solution in each measurement. The absorption spectra of RB in PBS were measured with a UV/Vis/NIR spectrophotometer (Lambda950, PerkinElmer, Waltham MA, USA).

\subsection{Excitation light sources}

A Q-switched $523 \mathrm{~nm}$ Nd:YLF laser (QG-523-500, Crystalaser Inc., Reno, USA) and a custom developed modulated $532 \mathrm{~nm}$ diode-pumped all-solidstate laser (DPSSL) (Institute of Semiconductors, Chinese Academy of Sciences, Beijing, China) were used as light sources to excite the PS, respectively. The Q-switched $523 \mathrm{~nm}$ laser provides high energy pulses with adjustable pulse repetition rates in range of $1-100 \mathrm{kHz}$. Typically, the pulse width of $523 \mathrm{~nm}$ laser was $20.7 \mathrm{~ns}$ at $10 \mathrm{kHz}$. The modulated $532 \mathrm{~nm}$ DPSSL can be operating in both CW and pulse modes. For pulse mode, the DPSSL was modulated between "on" and "off" state by a Transistor-Transistor-Logic (TTL) signal generated from a two-channel function/arbitrary waveform generator (DG1022U, Beijing RIGOL Technology Co., Ltd., Beijing, China). The minimum pulse width was determined to be about $10 \mu \mathrm{s}$, and the pulse repetition rates can range from $1 \mathrm{~Hz}$ to $15 \mathrm{kHz}$. The pulse width and repetition rate were measured using a digital storage oscilloscope (TDS3054C, Tektronix Inc., Beaverton, OR, USA) and a photodiode (PDM-400, Becker \& Hickl GmbH, Berlin, Germany). Figure 1 shows the normalized laser pulse of $523 \mathrm{~nm}$ and $532 \mathrm{~nm}$ (20\% duty cycle) pulsed laser at the repetition rate of $10 \mathrm{kHz}$. The output laser pulse shape of $532 \mathrm{~nm}$ DPSSL was not squarewave pulse due to the long rise and fall time.

\section{3. ${ }^{1} \mathrm{O}_{2}$ luminescence detection system}

The ${ }^{1} \mathrm{O}_{2}$ luminescence was measured by using a custom developed time-resolved NIR luminescence detection system, which was described in detail previously. ${ }^{12}$ Briefly, the excitation laser light was 
Effects of pulse width and repetition rate of pulsed laser on singlet oxygen luminescence

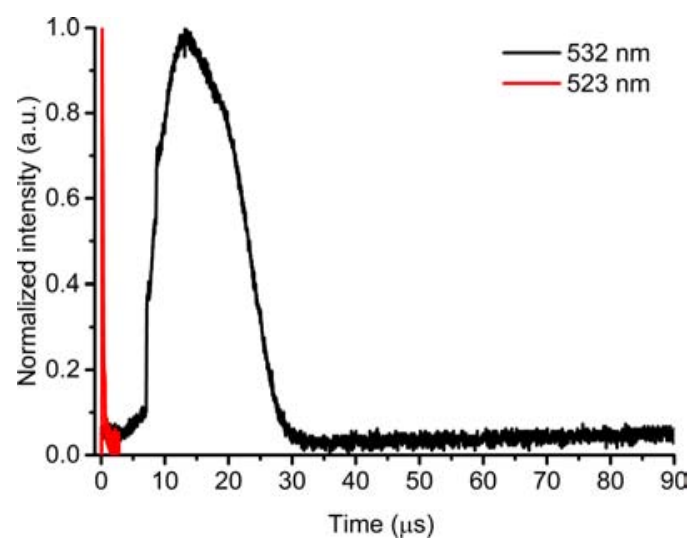

Fig. 1. The normalized laser pulse shape of $523 \mathrm{~nm}$ and $532 \mathrm{~nm}$ pulsed laser at the repetition rate of $10 \mathrm{kHz}$.

directed into the measured $2.5 \mathrm{ml}$ solution placed in a standard $10 \mathrm{~mm}$ pathlength quartz cuvette, and the beam diameter at the sample is about $1 \mathrm{~mm}$. The cuvette was open so that the solutions were exposed to room air at the top. The excited luminescence was collected at right angle to the excitation beam through a $1000 \mathrm{~nm}$ long-pass filter, the collection optics and the series of three NIR narrow-band filters centered at 1230, 1270 and $1310 \mathrm{~nm}$ (OD3 blocking, $20 \mathrm{~nm}$ full width at halfmaximum (FWHM); Omega Optical, Brattleboro, USA) that were placed in front of the NIR-photomultiplier tube (NIR-PMT, H10330-45, Hamamatsu Corp., Hamamatsu, Japan) with a constant operating voltage of $-900 \mathrm{~V}$. The PMT output pulses were pre-amplified and finally recorded in the fast photon counter (MSA-300, Becker \& Hickl GmbH, Berlin, Germany), which was triggered by synchronizing trigger signal of excitation laser. In order to achieve a sufficient signal-to-noise ratio (SNR), the laser power and irradiation time for each measurement were set to $20 \mathrm{~mW}$ and $30 \mathrm{~s}$, respectively. The three narrow-band filters allow sampling of the NIR spectrum across the ${ }^{1} \mathrm{O}_{2}$ luminescence peak at $1270 \mathrm{~nm}$ and background. The ${ }^{1} \mathrm{O}_{2}$ luminescence intensity at $1270 \mathrm{~nm}$ for $\mathrm{RB}$ in PBS was corrected for background by subtracting the average luminescence intensity of the $1230 \mathrm{~nm}$ and $1310 \mathrm{~nm}$ filters.

\subsection{Experimental protocols}

A series of pulse widths for modulated $532 \mathrm{~nm}$ DPSSL was obtained by adjusting the duty cycle for a square waveform from $10 \%$ to $50 \%$ in
Table 1. Pulse widths of excitation lasers.

\begin{tabular}{lcc}
\hline Wavelengths $(\mathrm{nm})$ & Mode & Pulse width \\
\hline 523 & Pulse & $20.7 \mathrm{~ns}$ \\
532 & Pulse & $10.7,14.0,19.9,28.0,36.0 \mu \mathrm{s}$ \\
532 & CW & \\
\hline
\end{tabular}

increments of $10 \%$ using the waveform generator. The pulse widths of excitation lasers were shown in Table 1. For evaluating the effect of repetition rates on the kinetics and production of ${ }^{1} \mathrm{O}_{2}$ luminescence, the time-resolved ${ }^{1} \mathrm{O}_{2}$ luminescence excited by modulated $532 \mathrm{~nm}$ DPSSL with repetition rates of $1,5,10$ and $15 \mathrm{kHz}$ was also investigated as compared to $\mathrm{CW}$ excitation. In addition, the obtained time-resolved ${ }^{1} \mathrm{O}_{2}$ luminescence curve and the corresponding time-integrated ${ }^{1} \mathrm{O}_{2}$ luminescence intensity after background subtraction were comparatively studied.

\subsection{Kinetic models for ${ }^{1} \mathrm{O}_{2}$ production}

The kinetics of the PDT photochemical reactions can be described by the following three coupled differential equations ${ }^{13}$ :

$$
\begin{gathered}
\frac{d\left[S_{1}\right]}{d t}=I \sigma\left[S_{0}\right]-\frac{\left[S_{1}\right]}{\tau_{s}}, \\
\frac{d\left[T_{1}\right]}{d t}=\frac{\Phi_{T}}{\tau_{s}}\left[S_{1}\right]-\frac{\left[T_{1}\right]}{\tau_{T}}, \\
\frac{d\left[{ }^{1} O_{2}\right]}{d t}=\frac{\Phi_{D}}{\Phi_{T} \tau_{T}}\left[T_{1}\right]-\frac{\left[{ }^{1} O_{2}\right]}{\tau_{D}},
\end{gathered}
$$

where $I$ is the excitation laser intensity in photons $\left(\mathrm{cm}^{-2} \mathrm{~s}^{-1}\right)$ and is a function of time, $\sigma$ is the molecular absorption cross-section of PS $\left(\mathrm{cm}^{-2}\right)$. $\left[S_{0}\right],\left[S_{1}\right]$ and $\left[T_{1}\right]$ are the concentrations of PS ground-state, singlet-state and triplet-state, respectively. $\Phi_{D}$ is the ${ }^{1} \mathrm{O}_{2}$ quantum yield and $\Phi_{T}$ is the PS triplet-state quantum yield. $\tau_{s}$ is the PS singlet-state lifetime, $\tau_{D}$ and $\tau_{T}$ are the lifetimes of ${ }^{1} \mathrm{O}_{2}$ and PS triplet-state, respectively. We have assumed that the $\left[S_{0}\right]$ and $\left[{ }^{3} \mathrm{O}_{2}\right]$ are independent of time.

For a sufficiently short $(<\sim 20 \mathrm{~ns})$ laser pulse excitation, the excitation laser pulse can be treated as an "instantaneous" source and the triplet-state PS molecules are created instantaneously after excitation (valid for $\tau_{s} \ll \tau_{T}$ ), the ${ }^{1} \mathrm{O}_{2}$ concentration as a function of time generated after laser pulse can 
be described as $^{13}$ :

$$
\left[{ }^{1} O_{2}\right]_{t}=N \sigma\left[S_{0}\right] \Phi_{D} \frac{\tau_{D}}{\tau_{T}-\tau_{D}}\left[\exp \left(\frac{-t}{\tau_{T}}\right)-\exp \left(\frac{-t}{\tau_{D}}\right)\right],
$$

where $N$ is the total number of incident photons per unit area (photons $\mathrm{cm}^{-2}$ ) at time $t=0$.

For a relatively long (i.e., 10.7-36 $\mu$ s used in the study) laser pulse excitation, Eq. (4) is no longer valid while laser is on. To gain a better understanding of ${ }^{1} \mathrm{O}_{2}$ production, we solved Eqs. (1)-(3) numerically using Matlab software (Matlab2010, MathWorks Inc., USA).

For CW excitation, the concentration of ${ }^{1} \mathrm{O}_{2}$ reaches steady-state when PS is continuously irradiated. In this case, the rate of ${ }^{1} \mathrm{O}_{2}$ production $I_{a} \Phi_{D}$ equals the rate of ${ }^{1} \mathrm{O}_{2}$ decay $k_{d}\left[{ }^{1} \mathrm{O}_{2}\right]_{s s},{ }^{14}$ and thus

$$
\left[{ }^{1} O_{2}\right]_{s s}=\frac{I_{a} \Phi_{D}}{k_{d}},
$$

where $I_{a}$ is the photon absorption rate, and $k_{d}$ is the decay rate of ${ }^{1} \mathrm{O}_{2}$.

\subsection{Data analysis}

The temporal profiles of ${ }^{1} \mathrm{O}_{2}$ luminescence were simulated by Matlab software, combined with Eqs. (1)-(3) for the $10.7 \mu$ s pulse excitation, Eq. (4) for the $20.7 \mathrm{~ns}$ pulse excitation and Eq. (5) for CW excitation, respectively. All the measured data were processed and analyzed using OriginPro 9.1 software (OriginLab Corp.). Data are presented as means \pm the standard deviation (SD) of at least three independent measurements. Statistical analysis was performed with two-tailed unpaired Student's $t$-test. Differences were considered statistically significant at $P<0.05$.

\section{Results and Discussion}

\subsection{Kinetics of ${ }^{1} \mathrm{O}_{2}$ production}

Figures 2(a)-2(c) show the representative time-resolved NIR luminescence curves for three individual wavelengths and the corresponding ${ }^{1} \mathrm{O}_{2}$ luminescence curve after background subtraction for $1.00 \mu \mathrm{M}$ RB in PBS with pulse width of $20.7 \mathrm{~nm}$ at $523 \mathrm{~nm}$, pulse width of $10.7 \mu \mathrm{s}$ at $532 \mathrm{~nm}$, CW at $532 \mathrm{~nm}$, respectively. Significant difference in kinetics of ${ }^{1} \mathrm{O}_{2}$ luminescence was found under the excitation with various pulse widths of nanosecond, microsecond and CW irradiation with power of
$20 \mathrm{~mW}$. The $1230 \mathrm{~nm}$ and $1310 \mathrm{~nm}$ filters provide the reference of background luminescence, while the $1270 \mathrm{~nm}$ filter contains underlying background luminescence and ${ }^{1} \mathrm{O}_{2}$ emission. Figure $2(\mathrm{~d})$ shows the time-integrated luminescence spectra by summing over all the luminescence counts for the three individual wavelengths, respectively. In each case, a significant spectra peak was observed at $1270 \mathrm{~nm}$, which is consistent with ${ }^{1} \mathrm{O}_{2}$ luminescence.

The kinetics of ${ }^{1} \mathrm{O}_{2}$ luminescence under $20.7 \mathrm{~ns}$ and $10.7 \mu \mathrm{s}$ pulse laser excitation were simulated using Eq. (4) and Eqs. (1)-(3), respectively. As shown in Figs. 3(a) and 3(b), the simulated data are in good agreement with the measured data, which implies that the equation models allow the prediction for the kinetics of ${ }^{1} \mathrm{O}_{2}$ luminescence with various pulse widths over a large range.

In the study, the $523 \mathrm{~nm}$ Q-switched pulsed laser produces short pulses $(20.7 \mathrm{~ns})$, which meets the requirement of sufficient short pulse laser excitation. It can be assumed that the triplet-state PS is created instantaneously after excitation, ${ }^{13}$ and the tripletstate PS then can react with the molecular oxygen to generate ${ }^{1} \mathrm{O}_{2}$. After the termination of the laser pulse, the kinetic of ${ }^{1} \mathrm{O}_{2}$ luminescence can be described by the difference of two exponentials, as shown in Eq. (4). The $532 \mathrm{~nm}$ modulated DPSSL provides a relatively longer laser pulses $(10.7 \mu \mathrm{s})$. The tripletstate PS continuously generates and populates ${ }^{1} \mathrm{O}_{2}$ when the laser is on. The kinetics of ${ }^{1} \mathrm{O}_{2}$ luminescence changed continuously with the excitation laser pulse shape. The temporal profiles of ${ }^{1} \mathrm{O}_{2}$ luminescence and PS fluorescence were also simulated by MathCAD software using a pulsed diode laser with standard square-wave pulses (pulse widths: $1-10 \mu \mathrm{s}),{ }^{16,17}$ and the intensity was found to be rapidly changed at the beginning and at the terminal of the square-wave laser pulse, respectively. However, the output laser pulse shape of $532 \mathrm{~nm}$ DPSSL was not square-wave pulse due to the long rise and fall time. As indicated in Fig. 3, no rapid changes in the ${ }^{1} \mathrm{O}_{2}$ luminescence were observed. For the $\mathrm{CW}$ excitation, the ${ }^{1} \mathrm{O}_{2}$ was generated continuously and its luminescence reached a steady state during irradiation, which was in accordance with Eq. (5).

\section{2. ${ }^{1} \mathrm{O}_{2}$ production varied with pulse width}

As shown in Fig. 4(a), the peak intensity of ${ }^{1} \mathrm{O}_{2}$ luminescence decreased with the increase in pulse 


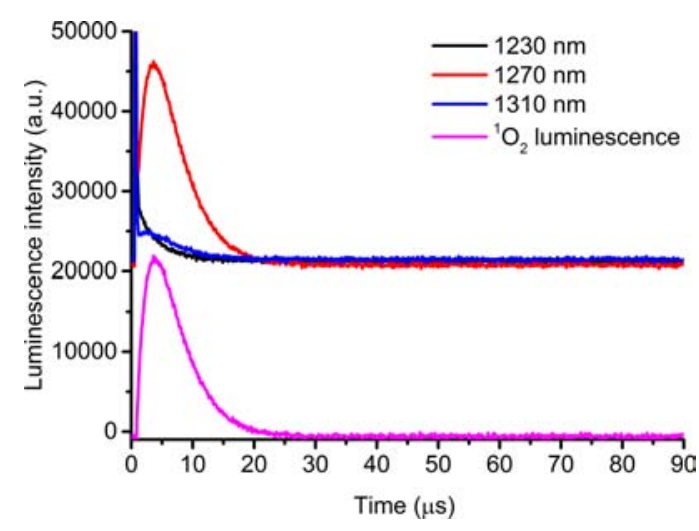

(a)

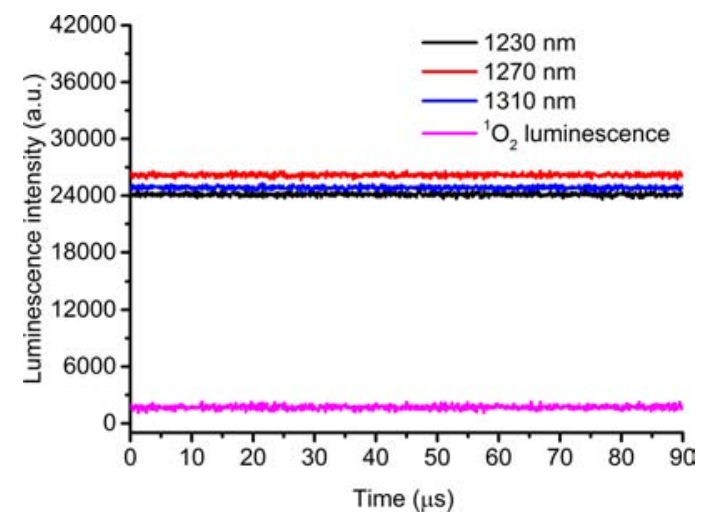

(c)

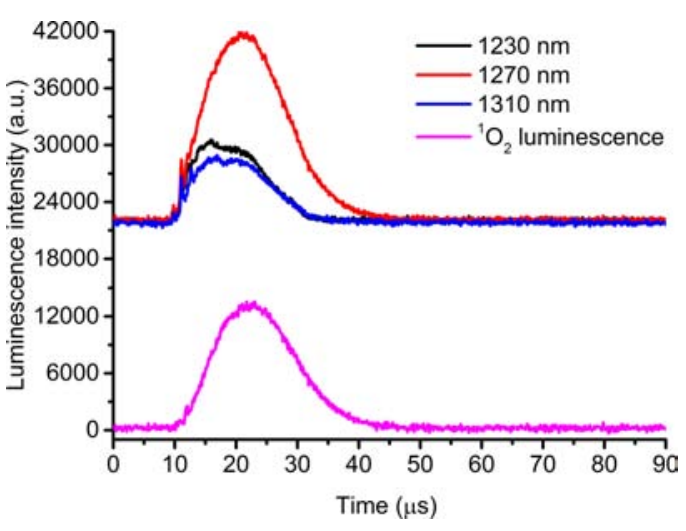

(b)

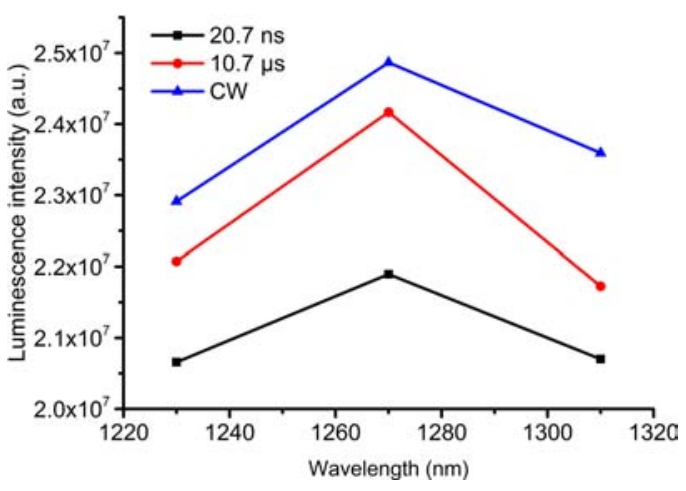

(d)

Fig. 2. Typical time-resolved luminescence spectra of three individual wavelengths (1230, 1270, $1310 \mathrm{~nm})$ and the corresponding ${ }^{1} \mathrm{O}_{2}$ luminescence from photo-irradiation of $1.00 \mu \mathrm{M} \mathrm{RB}$ in PBS with pulse widths of (a) $20.7 \mathrm{~ns}$ at $523 \mathrm{~nm}$ and (b) $10.7 \mu \mathrm{s}$ at $532 \mathrm{~nm}$, (c) $\mathrm{CW}$ at $532 \mathrm{~nm}$; (d) the time-integrated luminescence spectra of (a), (b) and (c).

width, while the duration of ${ }^{1} \mathrm{O}_{2}$ luminescence increased with the increase in pulse width. The ${ }^{1} \mathrm{O}_{2}$ production kept constant when $\mathrm{CW}$ mode was applied. Figure 4(b) indicates the time-integrated ${ }^{1} \mathrm{O}_{2}$

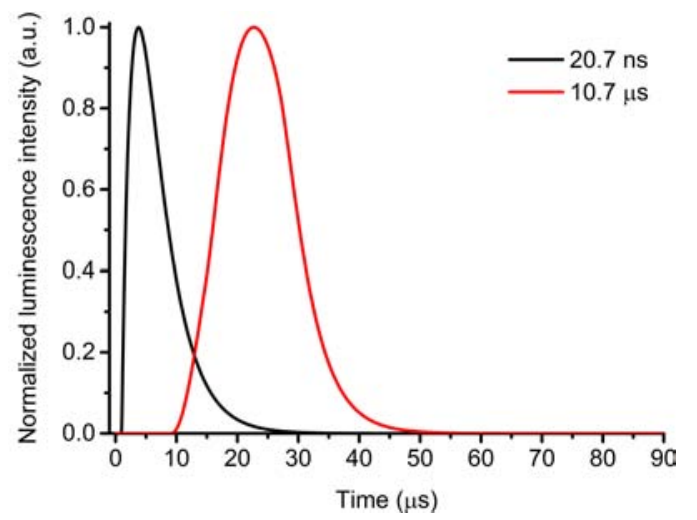

(a) luminescence intensity calculated by integrating the total ${ }^{1} \mathrm{O}_{2}$ luminescence counts after background subtraction. No significant difference $(P>0.05)$ in ${ }^{1} \mathrm{O}_{2}$ production was found under the excitation

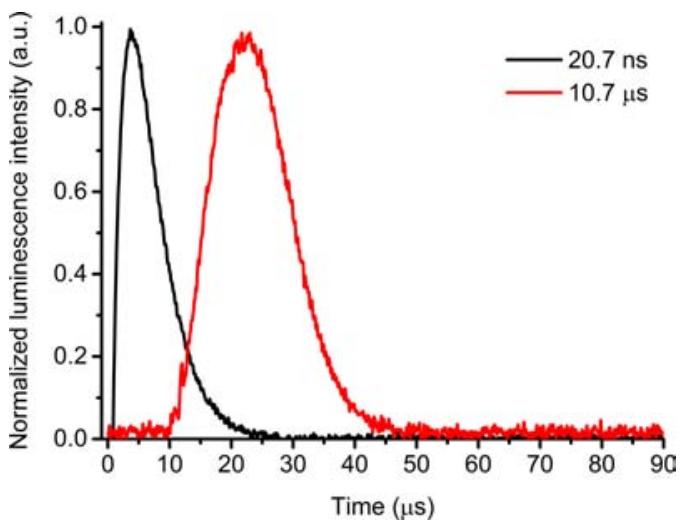

(b)

Fig. 3. Temporal profiles for ${ }^{1} \mathrm{O}_{2}$ luminescence with two different pulse widths excitation: (a) simulated curves using the equation models with $\tau_{D}=4 \mu \mathrm{s}, \tau_{T}=2 \mu \mathrm{s}, \Phi_{D}=0.76, \Phi_{T}=0.9^{12,15}$; and (b) the measured results. 


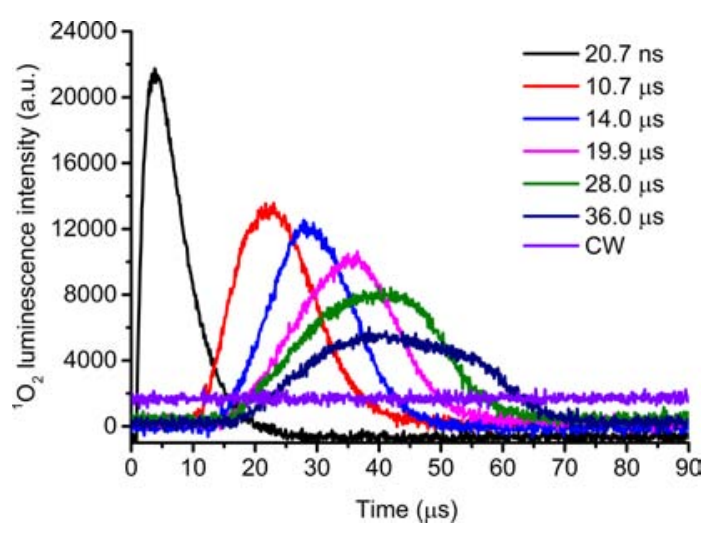

(a)

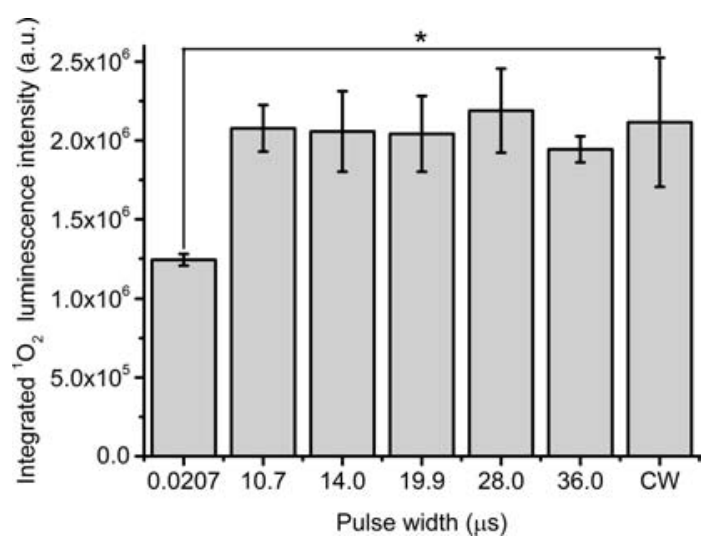

(b)

Fig. 4. (a) The typical time-resolved ${ }^{1} \mathrm{O}_{2}$ luminescence kinetics after background subtraction from RB $1.00 \mu \mathrm{M}$ in PBS, and (b) the corresponding integrated ${ }^{1} \mathrm{O}_{2}$ luminescence intensity with pulse width of $20.7 \mathrm{~ns}$ at $523 \mathrm{~nm}$, and pulse widths of 10.7 , 14.0, 19.9, 28, $36 \mu$ s and CW at $532 \mathrm{~nm} .{ }^{*} P<0.05$.

between the $532 \mathrm{~nm} \mathrm{CW}$ laser and $532 \mathrm{~nm}$ pulsed laser with various pulse widths of microsecond, while a significant difference $(P<0.05)$ in ${ }^{1} \mathrm{O}_{2}$ production was observed between $532 \mathrm{~nm}$ CW laser and $523 \mathrm{~nm}$ pulsed laser with pulse width of $20.7 \mathrm{~ns}$.

It should be noted that the absorbance of RB in PBS at $532 \mathrm{~nm}$ was measured to be 0.030 , which was about 1.5 times than 0.020 measured at $523 \mathrm{~nm}$. Our previous study showed that the ${ }^{1} \mathrm{O}_{2}$ production of RB in solution depend linearly on the absorbance up to 0.248 . ${ }^{3}$ The difference in ${ }^{1} \mathrm{O}_{2}$ production between $532 \mathrm{~nm} \mathrm{CW}$ laser and $523 \mathrm{~nm}$ pulsed laser with pulse width of $20.7 \mathrm{~ns}$ might be mainly attributed to the different absorbance of RB at different wavelengths in that no significant difference $(P>0.05)$ was found in ${ }^{1} \mathrm{O}_{2}$ production between them after the ${ }^{1} \mathrm{O}_{2}$ production of $523 \mathrm{~nm}$ pulsed laser multiplied by 1.5 (data not shown).

\section{3. ${ }^{1} \mathrm{O}_{2}$ production varied with pulse repetition rates}

As shown in Figs. 5(a) and 5(b), the time-integrated ${ }^{1} \mathrm{O}_{2}$ luminescence intensity was calculated by integrating the total ${ }^{1} \mathrm{O}_{2}$ luminescence counts after background subtraction. No significant difference $(P>0.05)$ was found in ${ }^{1} \mathrm{O}_{2}$ production between $\mathrm{CW}$ and pulsed $532 \mathrm{~nm}$ laser with various repetition rates.

${ }^{1} \mathrm{O}_{2}$ is known to the major cytotoxic agent in type-II PDT, and its amount is the direct indicator for PDT dosimetry. ${ }^{7}$ Wei et al. investigated the influence of the fluence rates $\left(15,45,135 \mathrm{~mW} / \mathrm{cm}^{2}\right.$ with two fluences $15 \mathrm{~J}$ and $75 \mathrm{~J}$, respectively) with light wavelength of $635 \mathrm{~nm}$ on the PDT treatment outcome for mouse tumor model by using chemiluminescence, which provided a selective mean for ${ }^{1} \mathrm{O}_{2}$

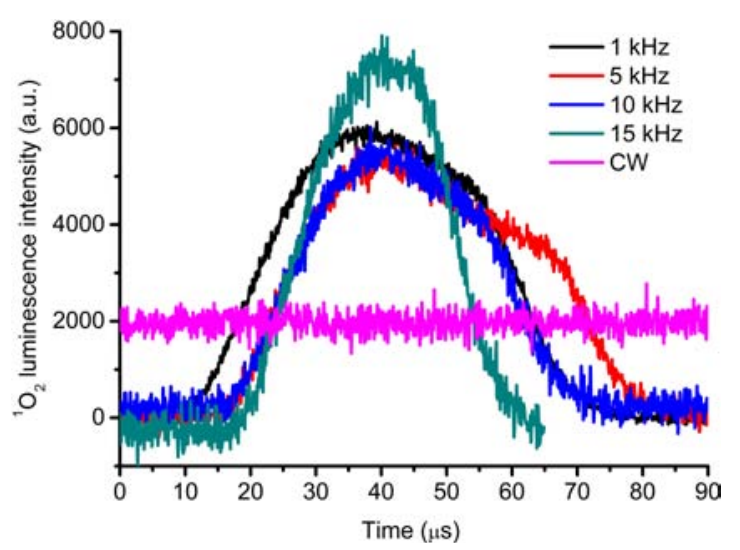

(a)

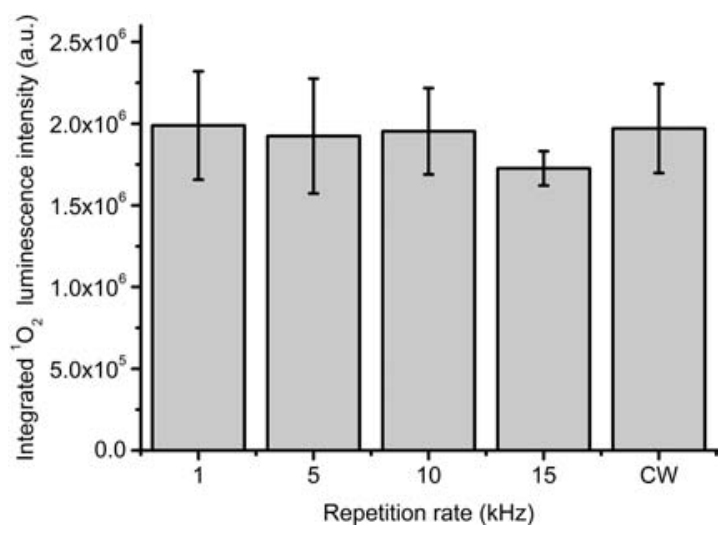

(b)

Fig. 5. (a) The typical time-resolved ${ }^{1} \mathrm{O}_{2}$ luminescence kinetics after background subtraction from RB $1.00 \mu \mathrm{M}$ in PBS, and (b) the corresponding time-integrated ${ }^{1} \mathrm{O}_{2}$ luminescence intensity with repetition rates of $1,5,10,15 \mathrm{kHz}$ and $\mathrm{CW}$ at $532 \mathrm{~nm}$. 
detection. ${ }^{18}$ The results indicate that a good correlation between the cumulative chemiluminescence and the PDT treatment outcome. ${ }^{18}$ In addition, less ${ }^{1} \mathrm{O}_{2}$ was produced at a higher light fluence rate. ${ }^{18}$ One possible reason is rapid depletion of oxygen due to PDT photochemical reactions that induced a local hypoxia. In our study, ${ }^{1} \mathrm{O}_{2}$ was directly measured by its luminescence at $1270 \mathrm{~nm}$ generated from photosensitization of $\mathrm{RB}$ solution in cuvette, which was exposed to room air at the top. Therefore, no significant reduction in ${ }^{1} \mathrm{O}_{2}$ was observed when using pulsed laser with high peak fluence.

Repetition rate and pulse width are two important parameters determining the effectiveness of PDT when pulsed lasers are utilized, ${ }^{19}$ and the peak power is inversely proportional to the repetition rate and pulse width. In principle, a very high peak power may saturate the PS and thus limit ${ }^{1} \mathrm{O}_{2}$ generation. ${ }^{20}$ According to a previous study, the effectiveness of pulsed excitation in PDT is comparable to that of $\mathrm{CW}$ excitation for the peak power density below $4 \times 10^{4} \mathrm{~W} / \mathrm{cm}^{2} .{ }^{20}$ Above the threshold, the PDT efficiency drops significantly. In this study, the maximum peak power density obtained from the Q-switch $523 \mathrm{~nm}$ laser with pulse width of $20.7 \mathrm{~ns}$ at the power of $20 \mathrm{~mW}$ was $1.2 \times 10^{4} \mathrm{~W} /$ $\mathrm{cm}^{2}$, which was below this threshold. Therefore, no significant decrease in the ${ }^{1} \mathrm{O}_{2}$ production was observed, as expected.

In fact, the clinical PDT efficacy could be influenced by the light penetration in tissues, PS concentration, molecular oxygen concentration and so on, all of which maybe varied during PDT treatments. ${ }^{21}$ In this study, all the measurements were performed in the RB solution. Therefore, we do not have to take into account the factors such as light penetration depth, PS distribution and so on, and allow focus on discussing the effects of the laser parameters on the kinetics and production of ${ }^{1} \mathrm{O}_{2}$, which is the critical cytotoxic species that determines the PDT efficacy. For the first time, the effects of laser pulse width range from nanosecond to $\mathrm{CW}$ on the kinetics and production of ${ }^{1} \mathrm{O}_{2}$ luminescence were directly compared. No significant difference was observed in ${ }^{1} \mathrm{O}_{2}$ production among various pulse widths and repetition rates with the same average irradiation power of $20 \mathrm{~mW}$, which implies that the efficacy of PDT using pulsed laser may be identical to the CW laser with the same wavelength and the same average fluence rate in solution. However, a number of studies compared
CW and pulsed lasers for PDT in vitro ${ }^{22-25}$ and in vivo ${ }^{26-29}$ and the pulsed laser irradiation found to be superior to, ${ }^{22,26}$ equivalent to, ${ }^{27-29}$ or inferior to $^{23-25} \mathrm{CW}$ laser in PDT efficacy by comparing the cytotoxicity ratio of cells or depth of necrosis. Possible reasons for the discrepancies are likely to be: first, various pulse widths $\left(10^{-1}-10^{-9} \mathrm{~s}\right)$ and pulse repetitions $\left(10^{1}-10^{4} \mathrm{~Hz}\right)$ were used in the previous studies, and the pulsed laser with short pulse width provides much higher peak power, which may saturate ${ }^{1} \mathrm{O}_{2}$ production and thus limit photodynamic effect; second, the peak intensity and duration of ${ }^{1} \mathrm{O}_{2}$ production varying with the pulse width observed in this study might lead to different cytotoxic effect in PDT. In this regard, the peak power should be carefully determined if ${ }^{1} \mathrm{O}_{2}$ production is saturated when using pulsed laser.

\section{Conclusions}

The effects of pulse width and repetition rate of pulsed laser on the kinetics and production of ${ }^{1} \mathrm{O}_{2}$ luminescence were quantitatively investigated during photosensitization, which was also compared to the CW laser excitation. Significant difference was found for the kinetics of ${ }^{1} \mathrm{O}_{2}$ luminescence under the excitation with various pulse widths of nanosecond, microsecond and CW excitation, while no significant difference was observed in ${ }^{1} \mathrm{O}_{2}$ production among various pulse widths and repetition rates with the same average irradiation power of $20 \mathrm{~mW}$. The results suggest that the PDT efficacy using pulsed laser may be identical to the $\mathrm{CW}$ laser with the same wavelength and the same average fluence rate below a threshold in solution.

\section{Acknowledgments}

This study was supported by the National Natural Science Foundation of China $(61108078,61450005$, 81171633, 61036014), the Industry Research Special Funds for Public Welfare Projects (2015SQ00057) and the Fujian Provincial Natural Science Foundation (2014J07008).

\section{References}

1. P. Agostinis, K. Berg, K. A. Cengel, T. H. Foster, A. W. Girotti, S. O. Gollnick, S. M. Hahn, M. R. Hamblin, A. Juzeniene, D. Kessel, M. Korbelik, 
J. Moan, P. Mroz, D. Nowis, J. Piette, B. C. Wilson, J. Golab, "Photodynamic therapy of cancer: An update," CA. Cancer J. Clin. 61(4), 250-281 (2011).

2. M. Scholz, R. Dedic, J. Valenta, T. Breitenbach, J. Hala, "Real-time luminescence microspectroscopy monitoring of singlet oxygen in individual cells," Photochem. Photobiol. Sci. 13(8), 1203-1212 (2014).

3. B. Li, H. Lin, D. Chen, M. Wang, S. Xie, "Detection system for singlet oxygen luminescence in photodynamic therapy," Chin. Opt. Lett. 8(1), 86-88 (2010).

4. M. T. Jarvi, M. J. Niedre, M. S. Patterson, B. C. Wilson, "The influence of oxygen depletion and photosensitizer triplet-state dynamics during photodynamic therapy on accurate singlet oxygen luminescence monitoring and analysis of treatment dose response," Photochem. Photobiol. 87(1), 223234 (2011).

5. J. C. Schlothauer, J. Falckenhayn, T. Perna, S. Hackbarth, B. Roder, "Luminescence investigation of photosensitizer distribution in skin: Correlation of singlet oxygen kinetics with the microarchitecture of the epidermis," J. Biomed. Opt. 18(11), 115001 (2013).

6. B. C. Wilson, M. S. Patterson, B. H. Li, M. T. Jarvi, "Correlation of in vivo tumor response and singlet oxygen luminescence detection in mTHPC-mediated photodynamic therapy," J. Innov. Opt. Heal. 8 (1), 1540006 (2015).

7. B. Li, H. Lin, D. Chen, B. C. Wilson, Y. Gu, "Singlet oxygen detection during photosensitization," J. Innov. Opt. Heal. 6(1), 1330002 (2013).

8. A. Felgenträger, F. P. Gonzales, T. Maisch, W. Bäumler, "Ion-induced stacking of photosensitizer molecules can remarkably affect the luminescence detection of singlet oxygen in Candida albicans cells," J. Biomed. Opt. 18(4), 045002 (2013).

9. J. C. Schlothauer, S. Hackbarth, L. Jäger, K. Drobniewski, H. Patel, S. M. Gorun, B. Röder, "Time-resolved singlet oxygen luminescence detection under photodynamic therapy relevant conditions: Comparison of ex vivo application of two photosensitizer formulations," J. Biomed. Opt. 17 (11), 115005 (2012).

10. L. Chen, L. Lin, Y. Li, H. Lin, Z. Qiu, Y. Gu, B. Li, "Effect of oxygen concentration on singlet oxygen luminescence detection," J. Lumin. 152(0), 98-102 (2014).

11. T. Maisch, J. Baier, B. Franz, M. Maier, M. Landthaler, R. M. Szeimies, W. Baumler, "The role of singlet oxygen and oxygen concentration in photodynamic inactivation of bacteria," Proc. Natl. Acad. Sci. USA 104(17), 7223-7228 (2007).
12. H. Lin, D. Chen, M. Wang, J. Lin, B. Li, S. Xie, "Influence of pulse-height discrimination threshold for photon counting on the accuracy of singlet oxygen luminescence measurement," J. Opt. 13(12), 125301 (2011).

13. M. Niedre, M. S. Patterson, B. C. Wilson, "Direct near-infrared luminescence detection of singlet oxygen generated by photodynamic therapy in cells in vitro and tissues in vivo," Photochem. Photobiol. 75(4), 382-391 (2002).

14. F. Wilkinson, W. P. Helman, A. B. Ross, "Rate constants for the decay and reactions of the lowest electronically excited singlet-state of molecularoxygen in solution - an expanded and revised compilation," J. Phys. Chem. Ref. Data 24(2), 6631021 (1995).

15. R. W. Redmond, J. N. Gamlin, "A compilation of singlet oxygen yields from biologically relevant molecules," Photochem. Photobiol. 70(4), 391-475 (1999).

16. S. Lee, L. Zhu, A. M. Minhaj, M. F. Hinds, D. H. Vu, D. I. Rosen, S. J. Davis, T. Hasan, "Pulsed diode laser-based monitor for singlet molecular oxygen," J. Biomed. Opt. 13(3), 034010 (2008).

17. S. Lee, D. H. Vu, M. F. Hinds, S. J. Davis, A. Liang, T. Hasan, "Pulsed diode laser-based singlet oxygen monitor for photodynamic therapy: In vivo studies of tumor-laden rats," J. Biomed. Opt. 13(6), 064035 (2008).

18. Y. Wei, J. Song, Q. Chen, "In vivo detection of chemiluminescence to monitor photodynamic threshold dose for tumor treatment," Photochem. Photobiol. Sci. 10(6), 1066-1071 (2011).

19. K. Seguchi, S. Kawauchi, Y. Morimoto, T. Arai, H. Asanuma, M. Hayakawa, M. Kikuchi, "Critical parameters in the cytotoxicity of photodynamic therapy using a pulsed laser," Lasers Med. Sci. 17 (4), 265-271 (2002).

20. H. J. Sterenborg, M. J. van Gemert, "Photodynamic therapy with pulsed light sources: A theoretical analysis," Phys. Med. Biol. 41(5), 835-849 (1996).

21. M. T. Jarvi, M. J. Niedre, M. S. Patterson, B. C. Wilson, "Singlet oxygen luminescence dosimetry (SOLD) for photodynamic therapy: Current status, challenges and future prospects," Photochem. Photobiol. 82(5), 1198-1210 (2006).

22. V. V. Klimenko, A. A. Bogdanov, N. A. Knyazev, A. A. Rusanov, M. V. Dubina, "Different photodynamic effect between continuous wave and pulsed laser irradiation modes in k562 cells in vitro," J. Phys.: Conf. Ser. 541(1), 012040 (2014).

23. S. Kawauchi, Y. Morimoto, S. Sato, T. Arai, K. Seguchi, H. Asanuma, M. Kikuchi, "Differences between cytotoxicity in photodynamic therapy using a pulsed laser and a continuous wave laser: Study of 
oxygen consumption and photobleaching," Lasers Med. Sci. 18(4), 179-183 (2004).

24. Y. Miyamoto, Y. Umebayashi, T. Nishisaka, "Comparison of phototoxicity mechanism between pulsed and continuous wave irradiation in photodynamic therapy," J. Photochem. Photobiol. B $\mathbf{5 3}$ (1-3), 53-59 (1999).

25. J. Chen, N. K. Mak, W. Leung, N. Cheung, Q. Peng, "Comparison of merocyanine 540-mediated photodynamic action on leukemia cells between pulsed and continuous wave light sources," J. Environ. Pathol. Toxicol. Oncol. 25(1-2), 217-222 (2006).

26. T. Amemiya, H. Nakajima, T. Katoh, H. Rakue, M. Miyagi, C. Ibukiyama, "Photodynamic therapy of atherosclerosis using YAG-OPO laser and Porfimer sodium, and comparison with using argon-dye laser," Jpn. Circ. J. 63(4), 288-295 (1999).
27. M. L. De Jode, J. A. McGilligan, M. G. Dilkes, I. Cameron, M. F. Grahn, N. S. Williams, "An in vivo comparison of the photodynamic action of a new diode laser and a copper vapour dye laser at 652 nm," Lasers Med. Sci. 11(2), 117-121 (1996).

28. M. Panjehpour, B. F. Overholt, R. C. DeNovo, M. G. Petersen, R. E. Sneed, "Comparative study between pulsed and continuous wave lasers for Photofrin photodynamic therapy," Lasers Surg. Med. 13(3), 296-304 (1993).

29. P. C. Rausch, F. Rolfs, M. R. Winkler, A. Kottysch, A. Schauer, W. Steiner, "Pulsed versus continuous wave excitation mechanisms in photodynamic therapy of differently graded squamous cell carcinomas in tumor-implanted nude mice," Eur. Arch. Otorhinolaryngol. 250(2), 82-87 (1993). 